Int. J. Electrochem. Sci., 15 (2020) $4494-4502$

\title{
Up-scalable synthesis of highly crystalline electroactive Ni-Co LDH nanosheets for supercapacitor applications
}

\author{
G.E. Nyongombe ${ }^{1}$, G.L. Kabongo ${ }^{1,2,3, *}$, L.L. Noto ${ }^{1}$, M.S. Dhlamini ${ }^{1, *}$ \\ ${ }^{1}$ Department of Physics, School of Science, CSET, University of South Africa, Private Bag X6, \\ Florida, 1710, Science Campus, Christiaan de Wet and Pioneer Avenue, Florida Park, \\ Johannesburg, South Africa \\ ${ }^{2}$ TS\&BHP S.E.N.C., Saint-Jean-sur-Richelieu, Québec J3B 6X4, Canada \\ ${ }^{3}$ Département de Physique, FNEA, Université Pédagogique Nationale, 8815 Kinshasa, R.D. Congo \\ *E-mail: leba.kabongo@gmail.com,dhlamms@unisa.ac.za
}

doi: $10.20964 / 2020.05 .33$

Received: 5 August 2019 / Accepted: 22 September 2019 / Published: 10 April 2020

The development of cost-effective and scalable synthetic methods is of paramount importance to achieve industrial application of energy conversion and storage devices based on layered double hydroxides (LDH). Herein, we synthesized NiCo-LDH nanosheets via a simple up-scalable coprecipitation method at relatively low temperature. Moreover, we used several characterization techniques to unveil the unique properties of the novel NiCo-LDH among which XRD, EDS, XPS and FT-IR. Consequently, we further investigated NiCo-LDH nanosheets using cyclic voltammetry (CV) and electrochemical impedance spectroscopy (EIS) to evaluate the electroactivity of the as-synthesized $\mathrm{NiCo}-\mathrm{LDH}$ for energy storage. Overall, the electrochemical test of the as-synthesized NiCo-LDH revealed remarkable performance exhibiting a specific capacitance as high as $2,140 \mathrm{Fg}^{-1}(5 \mathrm{mV} / \mathrm{s})$.

Keywords: NiCo-LDH nanosheets, co-precipitation, EIS, cyclic voltammetry, supercapacitor

\section{FULL TEXT}

(C) 2020 The Authors. Published by ESG (www.electrochemsci.org). This article is an open access article distributed under the terms and conditions of the Creative Commons Attribution license (http://creativecommons.org/licenses/by/4.0/). 